\title{
Somatostatin-14 Blocks the Hepatotrophic Effects of Insulin in the Rat ${ }^{1}$
}

\author{
Steven E. Raper, M.D., Piyush C. Kothary, M.S., and Norihiro KoKudo, M.D. \\ Department of Surgery, University of Michigan Medical Center, Ann Arbor, Michigan 48109
}

Presented at the Annual Meeting of the Association for Academic Surgery, Houston, Texas, November 14-17, 1990

\begin{abstract}
We hypothesized that somatostatin-14 (SS-14) might inhibit insulin-stimulated hepatic growth. Rat hepatocytes were isolated by a two-step collagenase perfusion technique and cultured on Matrigel. Differentiated hepatocyte function was documented by albumin synthesis. Hepatocytes were incubated with insulin in the presence or absence of SS-14. Hepatocyte proliferation was assessed by tritiated thymidine $\left(\left[{ }^{3} \mathrm{H}\right]\right.$ thy $)$ incorporation into DNA. $\left[{ }^{3} \mathrm{H}\right]$ thy incorporation was increased by $230 \%$ in the presence of insulin and was essentially abolished by the addition of SS-14. Insulin-stimulated cyclic-AMP accumulation was also decreased from 190 to $108 \%$ of control levels $(P<0.05)$ by the addition of SS-14. Pretreatment with pertussis toxin, which inactivates the inhibitory $G$-protein, $G_{i}$, blocked the effect of SS-14. Conclusions: (i) In the rat, SS-14 effectively blocks insulin-stimulated $\left[{ }^{3} \mathrm{H}\right]$ thy incorporation into DNA, possibly by blocking intracellular cAMP accumulation. (ii) Pertussis toxin blocks the growth inhibitory effects of SS-14, suggesting that inhibitory G proteins are involved in the mechanism of SS-14 action. Somatostatin may be useful in studying the role of second messengers in cell growth. (c) 1991 Academic Press, Inc.
\end{abstract}

\section{INTRODUCTION}

Most of our knowledge about growth control in hepatocyte cell culture has been derived from observing the action of growth stimulants such as insulin, epidermal growth factor, and glucagon [1]. The proliferative state is affected by the complex interactions of growth factors, ion flux, nutrient state, and growth inhibitors. In the case of hepatocytes, the inability to identify inhibitors and difficulties in distinguishing growth inhibition from cytotoxicity in cell culture have hampered the study of inhibitory growth regulation. Despite these difficulties, several compounds have been shown to inhibit hepatocyte growth, including transforming growth factor $\beta$ (TGF $\beta$ ), arginase, and adrenal steroids [2].

\footnotetext{
${ }^{1}$ This work was supported by NIH Grant 1 R29 DK42485-01 (SER) and a Career Development Award from the Society for Surgery of the Alimentary Tract (SER).
}

Somatostatin (SS-14) has been shown to inhibit proliferation of a number of normal and neoplastic cell types in culture. Somatostatin has been shown to inhibit growth of pancreatic acinar cells, rat thyroid follicular cells, and lymphocytes [3-5]. Somatostatin-14 and several analogs have also been shown to inhibit growth of cultured pancreatic tumor cells and can also inhibit proliferation of several breast cancer cell lines [6,7]. Although no work has been published looking at the effect of SS-14 on hepatocyte growth, it has been reported to inhibit rat liver regeneration in vivo [8]. Recently, SS-14 has been shown to inhibit insulin-stimulated but not triiodothyronine-stimulated growth of the well-differentiated human hepatoma (Hep3B) cell line [9].

Although no direct effects of SS-14 on hepatocyte growth have been previously reported, SS-14 appears to influence a number of hepatic functions. Several authors have documented a reduction in bile acid-independent canalicular bile flow in response to SS-14 in the intact rat as well as in an isolated, perfused rat liver [10]. In humans, continuous intravenous infusion of SS-14 decreases output of bile, bile acid, cholesterol, and phospholipid [11]. Evidence from several laboratories has recently shown that SS-14 may regulate liver function by blocking the effects of the intracellular second messenger, cyclic AMP [12, 13].

Based on evidence that somatostatin inhibits insulinstimulated Hep3B growth in vitro and also inhibits hepatic function and regeneration in vivo, we hypothesized that SS-14 might inhibit insulin-induced hepatocyte proliferation in culture and that this model might be a useful tool for studying the mechanism(s) responsible for hepatocyte proliferation.

\section{MATERIALS AND METHODS}

Chemicals. Collagenase (type I), media, $N$-2-hydroxyethylpiperazine- $N^{\prime}$-2-ethanesulfonic acid (Hepes), Hanks' buffer, and rat serum albumin were purchased from Sigma (St. Louis, MO). Somatostatin-14 and insulin were obtained from Peninsula Laboratories (Belmont, CA). Matrigel and Dispase were obtained from Collaborative Research (Bedford, MA). Anti-rat albumin was obtained from Organon (Organon Teknika 
Corp, PA). All reagents used for polyacrylamide gel electrophoresis and immunoblot analysis were electrophoresis grade and were obtained from Bio-Rad (Richmond, $\mathrm{CA}$ ) or Boeringer-Mannheim (Indianapolis, IN). $\left[{ }^{35} \mathrm{~S}\right]-$ Cysteine was obtained from Amersham (Arlington Heights, IL).

Hepatocyte isolation. Primary cultures of rat hepatocytes were isolated by the method of Gumucio [14]. Briefly, rat liver was portally perfused first with $\mathrm{Mg}^{2+}$ / $\mathrm{Ca}^{2+}$-free Hanks' buffer at $37^{\circ} \mathrm{C}$ and then with Eagle's minimal essential medium (EMEM) containing $0.05 \%$ collagenase (type I, Sigma). The liver was excised and placed in a petri dish containing fresh EMEM with $0.05 \%$ collagenase. Glisson's capsule was stripped and cells were released by gentle manipulation. The resulting crude preparation was filtered through $250-\mu \mathrm{m}$ and $100-\mu \mathrm{m}$ nylon mesh. Collagenase was inactivated with $0.5 \mathrm{ml}$ fetal calf serum. Viability was in excess of $90 \%$ as assessed by trypan blue exclusion.

$\left[{ }^{3} \mathrm{H}\right]$ Thymidine incorporation assay. $\quad\left[{ }^{3} \mathrm{H}\right]$ Thymidine incorporation into DNA was used as a marker for hepatocyte proliferation. Freshly isolated hepatocytes were plated at a density of $10^{5}$ per $16-\mathrm{mm}$ tissue culture dish coated with $250 \mu \mathrm{l}$ Matrigel, (laminin, heparan sulfate, type IV collagen) per well [15]. After a 24-hr attachment period in EMEM, fresh media including the various peptides was added. After six hr, $\left[{ }^{3} \mathrm{H}\right]$ thy $(2 \mu \mathrm{Ci} /$ well $)$ was added and the incubation was allowed to proceed overnight. Cells were removed from the Matrigel with Dispase, a neutral protease produced by Bacillus polymyxa. Half of the cell suspension was used for quantitation of incorporation of $\left[{ }^{3} \mathrm{H}\right]$ thy; the rest was used to measure DNA content. Cells for $\left[{ }^{3} \mathrm{H}\right]$ thy measurement were placed on GF/C Whatman filters, rinsed twice with $1 \mathrm{ml}$ of ice-cold $15 \%$ trichloroacetic acid, and then rinsed once with $70 \%$ EtOH. Filters were dried, placed in $10 \mathrm{ml}$ of Ecolume scintillation cocktail, and counted in a Beckman LS 6000LL scintillation counter. DNA content was measured with the diphenylamine reaction for desoxypentose.

Cyclic AMP assay. Freshly isolated hepatocytes $\left(10^{5} /\right.$ tube) were incubated with the appropriate reagents for $5 \mathrm{~min}$. At the end of the incubation period, test tubes were placed in a $4^{\circ} \mathrm{C}$ ice bath for $10 \mathrm{~min}$, vortexed, and centrifuged at $1800 \mathrm{~g}$ for $10 \mathrm{~min}$ at $4^{\circ} \mathrm{C}$. The pellet was precipitated with $15 \%$ TCA, ether extracted, and lyophilized. Cyclic AMP levels were measured by competitive protein binding assay using the Amersham kit (Arlington Heights, IL).

SDS-PAGE analysis. Media or protein standards were solubilized in sample buffer $(0.0625 \mathrm{M}$ Tris- $\mathrm{HCl}$ $(\mathrm{pH} 6.8), 2.3 \%$ SDS (w/v), $10 \%$ glycerol (w/v), $5 \% \beta$ mercaptoethanol (v:v), $5 \%$ Bromphenol blue) by heating at $100^{\circ} \mathrm{C}$ for $3 \mathrm{~min}$. Samples were subjected to electrophoresis in $7.5 \%$ acrylamide with $1 \%$ SDS after the method of Savion [16]. Some of the electrophoresed gels were fixed, stained with the Bio-Rad silver stain kit, and dried. Others were transferred to nitrocellulose membranes for immunoblot analysis.

Immunoblot analysis. Immunoblotting was performed after the method of Blake et al. [17]. Briefly, proteins from PAGE gels were transferred to nitrocellulose using electrophoretic transfer. After blocking with $20 \mathrm{mM}$ Tris-buffered saline $\left(\mathrm{pH} 7.5,25^{\circ} \mathrm{C}, 60 \mathrm{~min}\right)$ and $3 \%$ gelatin, the primary rabbit anti-rat albumin antibody was added at dilutions from 1:100 to 1:1000, with 1:500 giving the best results. A goat anti-rabbit IgG conjugated to alkaline phosphatase was used as the second antibody.

Statistical analysis. All analysis was done on a Macintosh II microcomputer with Statview II statistical analysis software. Analysis of variance (ANOVA) or Student's $t$ test was done for sample means, and Wilcoxon's signed rank test was done to compare mean percentages.

\section{RESULTS}

Viability and maintenance of differentiated hepatocyle function in culture. To rule out the possibility of cell loss as a cause for differences in subsequent experiments, hepatocytes $\left(1 \times 10^{5}\right)$ were incubated for $24 \mathrm{hr}$ in the presence of EMEM, insulin (20 $\mathrm{nM}$ ), somatostatin$14(10 \mathrm{nM})$, or both. On observation under the inverted microscope, cells were uniform in size and shape. Cells were removed from the tissue culture plates by Dispase treatment and cell number was analyzed by both hemocytometer and Coulter counter. No significant differences in cell number, shape, or percentage viability were seen after $24 \mathrm{hr}$ of treatment.

Albumin synthesis was used as a marker for differentiated hepatocyte function. Hepatocytes were incubated in EMEM in the presence or absence of insulin and/or somatostatin-14. $\left.{ }^{35} \mathrm{~S}\right] \mathrm{Cysteine}(1 \mu \mathrm{Ci})$ was added to the cultures. Media was aspirated at 24 and $48 \mathrm{hr}$ and analyzed by both immunoprecipitation and immunoblot techniques. Figure 1 shows the maintenance of incorporation of $\left[{ }^{35} \mathrm{~S}\right]$ cysteine into immunologically recognizable albumin, with an efficiency of incorporation of about $10 \%$ of the original dose of $\left[{ }^{35} \mathrm{~S}\right]$ cysteine. Figure 2 represents an immunoblot of media obtained from hepatocyte cultures after $24 \mathrm{hr}$, again revealing the presence of albumin.

The effect of somatostatin-14 on basal and insulinstimulated $\left[{ }^{3} \mathrm{H}\right]$ thymidine incorporation. The addition of insulin significantly increased the incorporation of $\left[{ }^{3} \mathrm{H}\right]$ thymidine into DNA in hepatocyte culture and this effect could be completely abolished by the addition of somatostatin-14 in a dose-dependent manner (Fig. 3). Autoradiographic study of the nuclear labeling index of cells exposed to EMEM with or without insulin or insulin and somatostatin-14 revealed a $245 \%$ increase in la- 


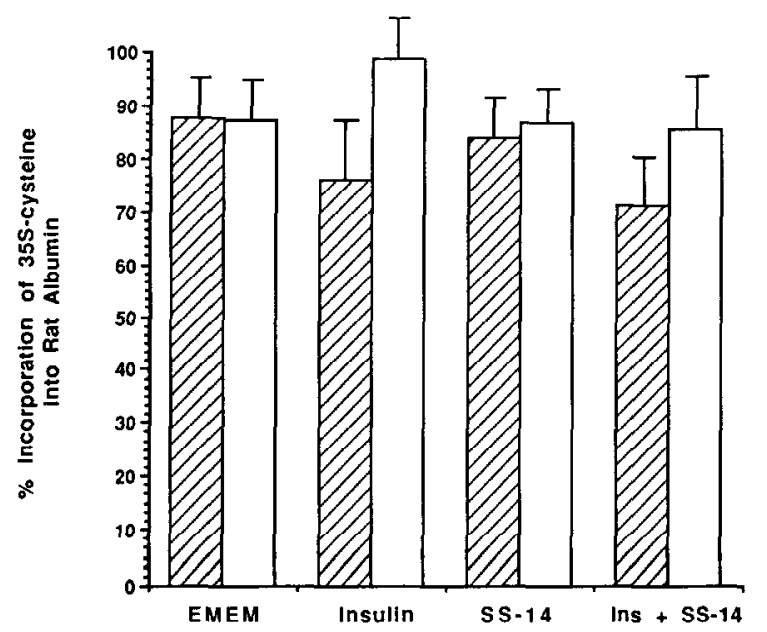

FIG. 1. Hepatocytes consistently synthesized albumin as measured by the incorporation of $\left[{ }^{35} \mathrm{~S}\right]$ cysteine into protein immunoprecipitable by an anti-rat albumin antibody. The data are expressed as a percentage of EMEM-treated hepatocytes. Shaded bars indicate a 24$\mathrm{hr}$ incubation; open bars indicate a 48-hr incubation. 'T'he data represent one of four experiments.

beled nuclei with insulin which could be reversed by the addition of somatostatin-14 (Fig. 4).

The effect of insulin and somatostatin-11 on cyclic AMP accumulation in hepatocyte culture. A small but reproducible increase in cAMP levels over that seen in cells grown in EMEM alone was detected in hepatocytes stimulated by insulin. This rise in cAMP could be counteracted by the addition of somatostatin-14 (Fig. 5).

The effect of pertussis toxin on somatostatin inhibition of thymidine incorporation and cAMP accumulation. Pertussis toxin (50 $\mathrm{ng}$ ) was added to hepatocyte cultures prior to the addition of insulin ( $20 \mathrm{n} M)$ or somatostatin$14(10 \mathrm{nM})$. Pertussis toxin was able to reverse the growth inhibitory effects of somatostatin-14 on thymidine incorporation (Fig. 6).

\section{DISCUSSION}

In this study, we have shown that somatostatin-14 inhibits insulin-stimulated DNA synthesis in a dose-dependent manner (Fig. 3). This effect did not result from

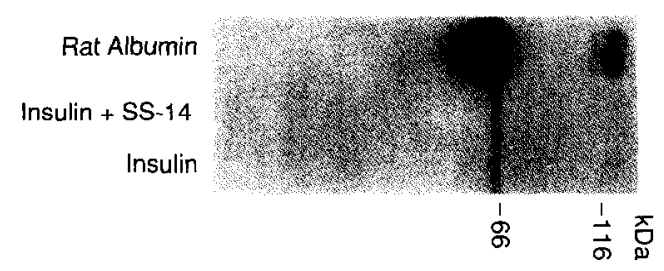

FIG. 2. Immunoblot of media from rat hepatocytes incubated on Matrigel. Note the presence of a protein band that stains positive for the rabbit anti-rat albumin antibody in the presence of insulin or somatostatin. The data are representative of three experiments. (SS-14, somatostatin-14).

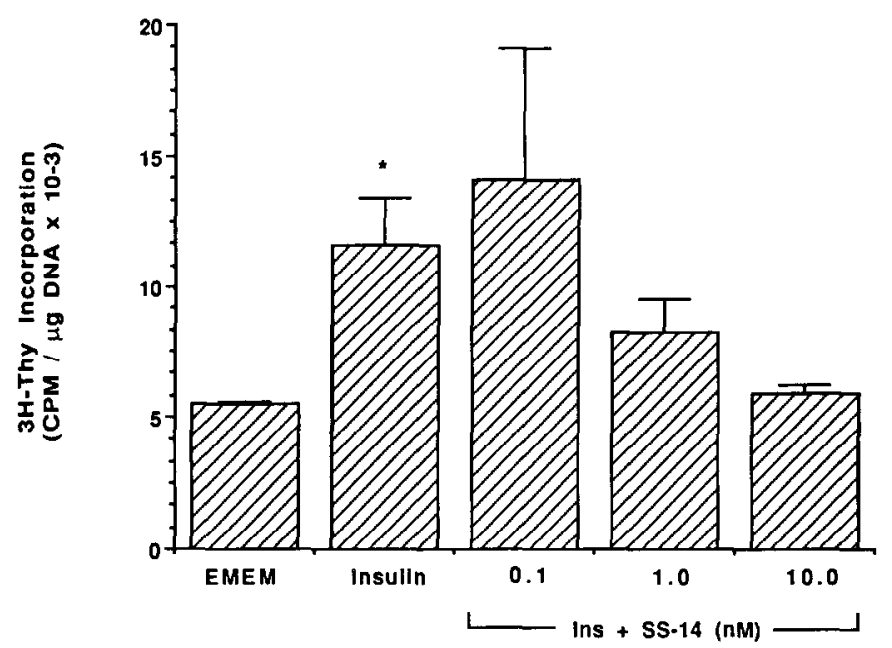

FIG. 3. Inhibition of insulin-stimulated thymidine incorporation by somatostatin-14. Hepatocytes $\left(10^{5} /\right.$ well) were incubated with or without insulin (Ins, $20 \mathrm{nM}$ ) and increasing doses of somatostatin-14 (SS-14). The data are representative of six experiments $\left({ }^{*} P \leqslant 0.05\right)$.

a toxic injury at the doses used, since the cells appeared viable, cell numbers were similar, and albumin synthesis was not adversely affected. To avoid the possible growth effects of uncharacterized serum components that might affect growth regulation, cells were allowed to grow in media for $24 \mathrm{hr}$ before any growth studies were performed [18]. This allowed us to carefully analyze the effects of insulin and somatostatin-14 on thymidine incorporation and cAMP content. Inhibition of hepatic regeneration by somatostatin has previously been reported in the $70 \%$ hepatectomy rat model; however, it is

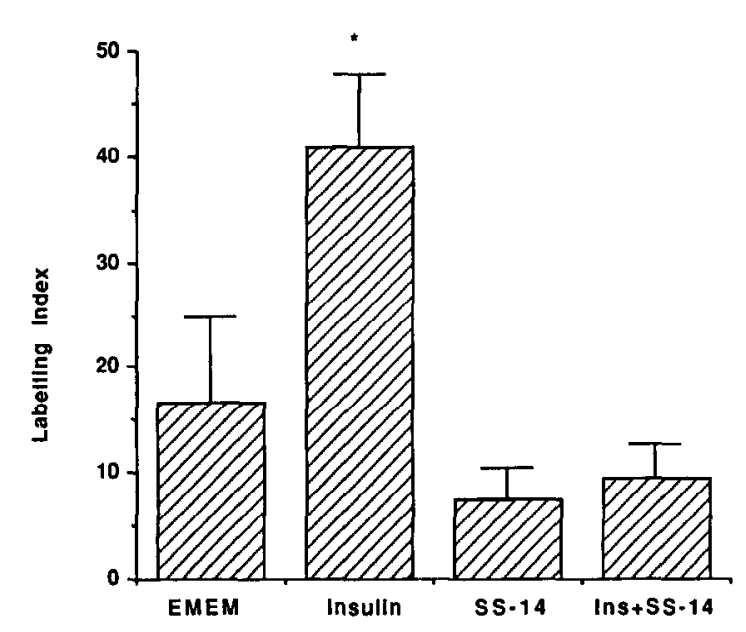

FIG. 4. Labeling index of hepatocytes treated with insulin (Ins, $20 \mathrm{nM}$ ) and somatostatin-14 (SS-14, $10 \mathrm{nM}$ ). The labeling index was calculated as the number of nuclei containing autoradiographic grains divided by the total number of counted nuclei. The data represent photographs of six wells for each treatment and an average of 150 nuclei in each well. Insulin-treated hepatocytes had a significantly higher labeling index when compared to the other treatment groups $(P$ $<0.05$ ) 
impossible to determine whether or not somatostatin was exerting a direct or indirect effect on the liver remnant [8].

The ability of somatostatin to inhibit hepatocyte growth is consistent with its anti-proliferative effects on other cultured cell lines such as mouse splenocytes and human blood T-lymphocytes $[19,20]$. Somatostatin has also been shown to inhibit proliferation of FRTL5 rat follicular thyroid cells [5]. Somatostatin can also inhibit certain tumors in several in vivo and in vitro model systems and has lead to speculation that it may be potentially useful in the treatment of certain neoplasms.

Somatostatin appears to inhibit cell growth by both cyclic AMP-dependent and -independent mechanisms. Somatostatin has been shown to inhibit hepatocyte proliferation induced by isobutyl methyl-xanthine and dibutyryl cyclic AMP, both of which act via cyclic AMPdependent mechanisms [21]. Our data show that pretreatment of hepatocytes by pertussis toxin, which increases adenyl cyclase activity by inactivating an inhibitory $G$ protein, blocks the inhibitory effect of somatostatin (Fig. 6). Although somatostatin is generally thought to act partly by decreasing cellular cAMP levels, non-cAMP-dependent effects have recently been described [22]. Inhibition of insulin-like growth factor-Istimulated FR'TL5 cell growth by somatostatin has been demonstrated and appears to be independent of cAMP pathways [5].

The effect of insulin on hepatic cyclic AMP levels has been studied by several investigators. Jefferson et al. were unable to document stimulation of hepatic cAMP by insulin [23]. Loten et al. showed that insulin activated a low $K_{m}$ hepatic phosphodiesterase which could decrease hepatic cAMP [24]. These studies, however, were performed at 10 to $30 \mathrm{~min}$ after incubation with insulin.

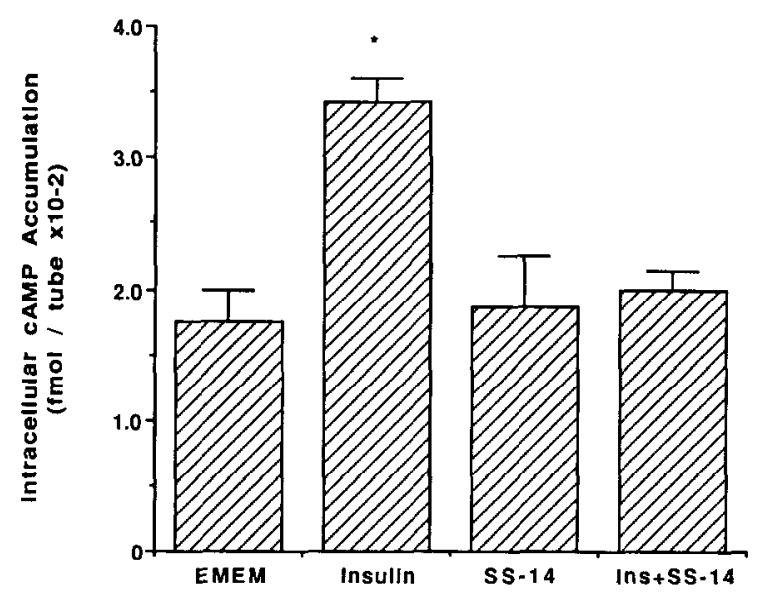

FIG. 5. Effect of insulin (Ins) and somatostatin-14 (SS-14) on hepatic cAMP levels. Hepatocytes $\left(1 \times 10^{5}\right)$ were incubated for 5 min with insulin $(20 \mathrm{nM}), \mathrm{SS}-14(10 \mathrm{nM})$, or both and then analyzed for cAMP. Insulin-treated hepatocytes had a significantly higher cAMP content when compared to the other treatment groups $(P<0.05)$. The data represent one of five experiments.

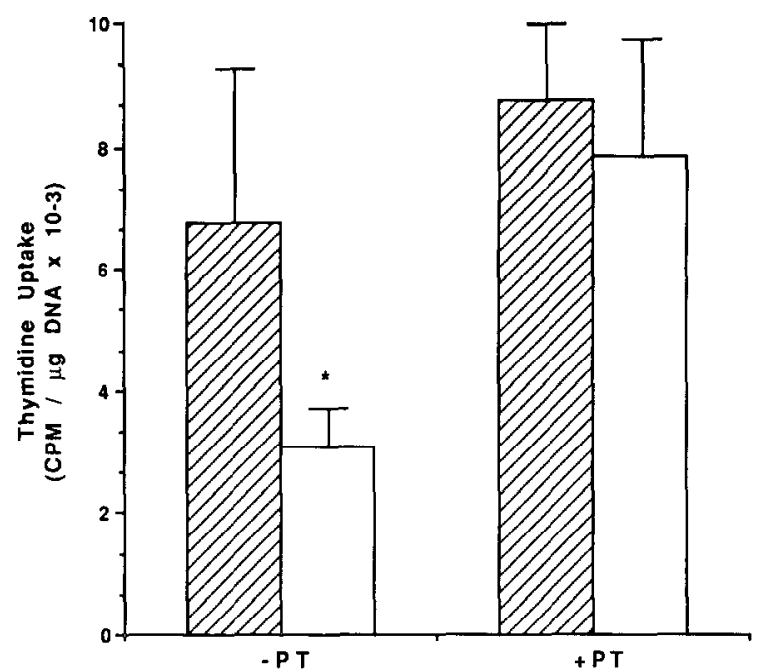

FIG. 6. Effect of pertussis toxin (PT) on the anti-proliferative effect of somatostatin. Hepatocytes $\left(10^{5} /\right.$ well) were preincubated with pertussis toxin ( $50 \mathrm{ng}$ ) or media. The hatched bars indicate cells treated with insulin $(20 \mathrm{nM})$. The open bars indicate cells treated with insulin $(20 \mathrm{n} M)$ and somatostatin-14 (10 $\mathrm{n} M)$. The data are representative of three experiments.

In the present study, we observed a small but reproducible increase in hepatic cAMP levels at 5 min after insulin stimulation. This observation is consistent with the findings of Gettys et al., who used hepatocytes preloaded with a hydrolyzable cAMP analog and documented increased cAMP levels at $0.5-2.0 \mathrm{~min}$ followed by a plateau at $5 \mathrm{~min}$ and a decline to baseline by $7 \mathrm{~min}$ and beyond [25]. This early but transient increase in hepatocyte cAMP after insulin treatment may provide the signal for hepatocytes to initiate mitosis [26].

Insulin has been shown to antagonize the effects of glucagon on hepatic carbohydrate metabolism despite the synergistic actions of insulin and glucagon on hepatocyte proliferation. This argues against the possibility that alteration of cellular cAMP levels is the major mechanism responsible for the hepatotrophic effects of insulin. More likely, insulin action and the inhibitory effects of somatostatin on insulin action are mediated through cyclic AMP-independent pathways such as protein phosphorylation or calcium influx. The synergistic effects of insulin, glucagon, and epidermal growth factor on hepatocyte growth suggest that each may act through different mechanisms [27].

In summary, somatostatin exerts an anti-proliferative effect on insulin-stimulated hepatocytes in vitro. The ability to identify growth inhibitory factors using an in vitro hepatocyte model will hopefully facilitate further studies of the intracellular mechanisms responsible for control of hepatic regeneration.

\section{REFERENCES}

1. McGowan, J. A. Hepatocyte proliferation in culture. In A. Guillozo and C. Guigen-Guillozo (Eds.), Research in Isolated and Cul- 
tured Hepatocytes. INSERM: John Libbey Eurotext, 1986. Pp. 14-38.

2. Carr, B. I., Hayashi, I., Branum, E. L., and Moses, H. L. Inhibition of DNA synthesis in rat hepatocytes by platelet-derived type B transforming growth factor. Cancer Res. 46: 2330, 1986.

3. Morisset, J. Somatostatin: A potential antigrowth factor for the endocrine pancreas. Regul. Pept. 10: 11, 1984.

4. Sreedharan, S. P., Kodama K. T., Peterson, K. E., and Goetzl, E. J. Distinct subsets of somatostatin receptors on cultured human lymphocytes. J. Biol. Chem. 264: 949, 1989.

5. Tsuzaki, S., and Moses, A. C. Somatostatin inhibits deoxyribonucleic acid synthesis induced by both thyrotropin and insulin-like growth factor-I in FRTL5 cells. Endocrinology 126: 3131, 1990.

6. Liebow, C., Reilly, C., Serrano, M., and Schally, A. V. Somatostatin analogues inhibit growth of pancreatic cancer by stimulating tyrosine phosphatase. Proc. Natl. Acad. Sci. USA 86: 2003, 1989.

7. Setyono-Han, B., Henkelman, M. S., Foekens, J. A., and Klijn, J. G. M. Direct inhibitory effects of somatostatin analogs on the growth of human breast cancer cells. Cancer Res. 47: 1566, 1987.

8. Goldman, A. L. Influence of somatostatin on hepatic regeneration in the adult rat. Surg. Forum 29: 402, 1978.

9. Chou, C. K., Ho, L. T., Ting, L. P., Hu, C., Su, T. S., Chang, W. C., Suen, C. S., Huang, M. Y., and Chang, C. Selective suppression of insulin-induced proliferation of cultured human hepatoma cells by somatostatin. J. Clin. Invest. 79: 175, 1987.

10. Ricci, G. L., and Fevery, J. Cholestatic action of somatostatin in the rat: Effect on the different fractions of bile secretion. Gastroenterology 81: 552, 1981.

11. Magnusson, I., Einarsson, K., Angelin, B., Nyberg, B., Bergstrom, K., and Thulin, L. Effects of somatostatin on hepatic bile formation. Gastroenterology 96: 206, 1989.

12. Catalan, R. E., Martinez, A. M., and Aragones, M. D. Evidence for a role of somatostatin in lipid metabolism of liver and adipose tissue. Regul. Pept. 8: 147, 1984.

13. Sheridan, M. A., and Bern, H. A. Both somatostatin and the caudal neuropeptide urotensin II stimulate lipid mobilization from coho salmon liver incubated in vitro. Regul. Pept. 14: 333, 1986.

14. Gumucio, J. J., May, M., Dvorak, C., Chianale, J., and Massey, $\mathrm{V}$. The isolation of functionally heterogeneous hepatocytes of the proximal and distal half of the liver acinus in the rat. Hepatology 6: $932,1986$.
15. Bissell, D. M., Arenson, D. M., Maher, J. J., and Roll, F. J. Support of cultured hepatocytes by a laminin-rich gel: Evidence for a functionally significant subendothelial matrix in normal rat liver. J. Clin. Invest. 79: 801, 1987.

16. Savion, N., Vlodavsky, I., and Gospodarowicz, D. Nuclear accumulation of epidermal growth factor in cultured bovine corneal endothelial and granulosa cells. J. Biol. Chem. 256: 1149, 1981.

17. Blake, M. S., Johnston, K. H., Russell-Jones, G. J., and Gotschlitch, E. C. A rapid, sensitive method for detection of alkaline phosphatase conjugated anti-antibody on western blots. Anal. Biochem. 136: 175, 1984.

18. Hayashi, I., and Carr, B. I. DNA synthesis in rat hepatocytes: Inhibition by a platelet factor and stimulation by an endogenous factor. J. Cell. Physiol. 122: 82, 1985.

19. Pawlikowski, M., Stepien, II., Kunert-Radek, J., Zelazowski, P., and Schally, A. V. Immunomodulatory action of somatostatin. Ann. N.Y. Acad. Sci. 496: 233, 1987.

20. Payan, D. G., Hess, C. A., and Goetzl, E. J. Inhibition by somatostatin of the proliferation of T-lymphocytes and MOLT-4 lymphoblasts. Cell. Immunol. 84: 433, 1984.

21. Kokudo, N., Kothary, P. C., Eckhauser, F. E., and Raper, S. E. Inhibitory effects of somatostatin on hepatocyte proliferation are mediated by cyclic AMP. Submitted for publication.

22. Reisine, T. Multiple mechanisms of somatostatin inhibition of adrenocorticotropin release from mouse anterior pituitary tumor cells. Endocrinology 116: 2259, 1985.

23. Jefferson, L. S., Exton, J. H., Butcher, R. W., Sutherland, E. W., and Park, C. R. Role of adenosine $3^{\prime}, 5^{\prime}$-monophosphate in the effects of insulin and anti-insulin serum on liver metabolism. $J$. Biol. Chem. 243: 1031, 1968.

24. Loten, E. G., Assimacopoulos-Jeannet, F. D., Exton, J. H., and Park, C. R. Stimulation of a low $K_{m}$ phosphodiesterase from liver by insulin and glucagon. J. Biol. Chem. 253: 746, 1978.

25. Gettys, T. W., Blackmore, P. F., and Corbin, J. D. An assessment of phosphodiesterase activity in situ after treatment of hepatocytes with hormones. Am. J. Physiol. 254: E449, 1988.

26. Rixon, R. H., and Whitfield, J. F. The possible cyclic AMP-dependence of an early prereplicative event that determines mitosis in regenerating rat liver. J. Cell. Physiol. 124: 397, 1985.

27. McGowan, J. A., Strain, A. J., and Bucher, N. L. R. DNA synthesis in primary cultures of adult rat hepatocytes in a defined medium: Effect of epidermal growth factor, insulin, glucagon, and cyclic AMP. J. Cell. Physiol. 180: 353, 1981. 